\title{
Methoxylated and hydroxylated polybrominated diphenyl ethers in surface sediments from the southern Yellow Sea: spatial distribution and potential producers
}

\author{
Ying Fan, ${ }^{\mathrm{A}, \mathrm{C}}$ Jing Lan, ${ }^{\mathrm{B}}$ Jiaokai Wang, ${ }^{\mathrm{A}}$ Zongshan Zhao, ${ }^{\mathrm{A}, \mathrm{E}}$ Meixun Zhao ${ }^{\mathrm{A}}$ \\ and Guibin Jiang \\ A Key Laboratory of Marine Chemistry Theory and Technology (Ocean University of China), \\ Ministry of Education and Qingdao Collaborative Innovation Center of Marine Science \\ and Technology, Qingdao 266100, China. \\ ${ }^{\mathrm{B}}$ College of Chemistry and Pharmaceutical Sciences, Qingdao Agricultural University, \\ Qingdao 266109, China. \\ CJiangxi Institute of Analysing and Testing, Nanchang 330029, China. \\ DState Key Laboratory of Environmental Chemistry and Ecotoxicology, Research Centre \\ for Eco-Environmental Sciences, Chinese Academy of Sciences, PO Box 2871, \\ Beijing 100085, China. \\ ECorresponding author. Email: zhaozs@qibebt.ac.cn; zhaozongshan@ouc.edu.cn
}

\begin{abstract}
Environmental context. Methoxylated and hydroxylated polybrominated diphenyl ethers are of increasing concern owing to their global distribution and potential ecological risks. We investigated the spatial distribution and sources of these brominated compounds in surface sediments from the southern Yellow Sea, China. The results suggest that marine phytoplankton may be the potential producers of these compounds, thereby providing new insights into their occurrence and provenance in marine environments.
\end{abstract}

\begin{abstract}
Methoxylated polybrominated diphenyl ethers (MeO-PBDEs) and hydroxylated polybrominated diphenyl ethers (OH-PBDEs) have recently caused worldwide concern; however, there have been very limited studies on their presence in marine sediments. In the present study, MeO-PBDEs, OH-PBDEs and phytoplankton biomarkers were determined in surface sediments from the southern Yellow Sea. MeO-PBDEs and OH-PBDEs are ubiquitous in southern Yellow Sea sediments, with total contents ranging from 43.0 to $571.4 \mathrm{pg} \mathrm{g}^{-1}$ dry weight. High contents of these compounds mainly concentrated in the central southern Yellow Sea basin, and their spatial distributions generally presented a seaward-increasing trend. By comparing with total organic carbon and terrestrial organic matter contributions in sediments, these compounds were inferred to originate mainly from marine production rather than from terrigenous inputs. Statistical analysis shows that there are significant correlations between MeO-PBDEs, OH-PBDEs and phytoplankton biomarkers, indicating that MeO-PBDEs and OH-PBDEs are mainly natural compounds, and the phytoplankton are likely to be their potential producers in the southern Yellow Sea, especially for dinosterol.
\end{abstract}

Additional keywords: MeO-PBDEs, OH-PBDEs, phytoplankton biomarker.

Received 15 November 2014, accepted 22 January 2015, published online 22 April 2015

\section{Introduction}

Polybrominated diphenyl ethers (PBDEs), used as brominated flame retardants in various household and industrial products for several decades, have emerged as contaminants owing to their ubiquitous environmental occurrence and potential adverse effects on ecosystems and human health. ${ }^{[1]}$ Their derivatives and structural analogues, namely, MeO-PBDEs and $\mathrm{OH}-$ PBDEs, have attracted increasing concern in recent years. OHPBDEs are structurally similar to the thyroid hormones. Several in vitro exposure experiments have shown that OH-PBDEs exhibit higher neurotoxicity and endocrine-disrupting potency than PBDEs, ${ }^{[2,3]}$ as well as greater dioxin-like activity than MeO-PBDEs. ${ }^{[4]}$ Further, MeO-PBDEs exert stronger effects on the mRNA abundance of steroidogenic enzymes than $\mathrm{OH}-$ PBDEs in the H295R cell line. ${ }^{[5]}$

$\mathrm{MeO}-\mathrm{PBDEs}$ and $\mathrm{OH}-\mathrm{PBDEs}$ have been detected in various biotic media, such as algae, ${ }^{[6-9]}$ fish, ${ }^{[10,11]}$ marine animals, ${ }^{[12-14]}$ human hepatocytes, ${ }^{[15]}$ breast milk ${ }^{[16]}$ and human blood. ${ }^{[17]}$ 6-OH-BDE47, 2'-OH-BDE68, 6-MeO-BDE47 and 2'-MeOBDE68, for example, are some of the most common and dominant congeners in the biota. Congeners with $\mathrm{OH}-$ or $\mathrm{MeO}$ - functional groups substituted at the ortho position of the diphenyl ether backbone are natural compounds, as previously determined by ${ }^{14} \mathrm{C}$ isotope techniques ${ }^{[18,19]}$ and in vitro and in vivo laboratory exposures. ${ }^{[20,21]}$ Fairly high levels of these natural compounds have been observed in numerous 
marine species potentially from bioaccumulation through the food web. ${ }^{[13,22,23]}$

Despite the interesting characteristics of MeO-PBDEs and $\mathrm{OH}-\mathrm{PBDE}$, only a few studies on these compounds in marine abiotic environments have been reported. ${ }^{[23-27]}$ Marine sediment is one of the most important reservoirs for various anthropogenic pollutants and thus is their secondary source because of resuspension from disturbance. Sedimentary $\mathrm{OH}-$ PBDEs and MeO-PBDEs could be important contributors to the bioaccumulation of these natural compounds in marine organisms. Zhang et al. ${ }^{[23]}$ assessed MeO-PBDE and OH-PBDE accumulation from sediments to organisms in the marine food web of Liaodong Bay using the biota-sediment accumulation factor (BSAF). BSAFs of MeO-PBDEs and OH-PBDEs for invertebrates were 0.14-7.2 and 0.017-6.3 respectively. Therefore, sedimentary MeO-PBDEs and OH-PBDEs are potential threats to marine ecosystems owing to their resuspension and bioaccumulation.

As previously reported, almost all of the natural organobromines are produced by marine organisms, including bacteria, plants and animals. ${ }^{[28]}$ In marine environments, total and specific phytoplankton productivity can be reflected by sedimentary phytoplankton biomarkers (PBs) such as chlorins, loliolide, isololiolide, sterols, alkenones and alkyl diols. ${ }^{[29-31]}$ Based on ${ }^{14} \mathrm{C}$ isotope analysis, Guitart et al. ${ }^{[19]}$ proposed that there are unidentified producers thriving on the surface of the ocean as planktonic organisms and synthesising $\mathrm{MeO}-\mathrm{PBDEs}$ and $\mathrm{OH}-$ PBDEs. Considering many $\mathrm{MeO}-\mathrm{PBDEs}$ and $\mathrm{OH}-\mathrm{PBDEs}$ have been isolated from algae, the relationships between these brominated compounds and PBs derived from once-living phytoplankton, which is the foundation of the marine food web, may provide valuable information to better understand the origins of these brominated compounds.

In the present study, the contents of MeO-PBDEs, OHPBDEs and PBs of brassicasterol, dinosterol and alkenones were investigated in surface sediments from the southern Yellow Sea (SYS). The objectives were to investigate the occurrence and spatial distribution, and possible producers of MeO-PBDEs and OH-PBDEs, and to reveal the factors influencing their accumulation in the SYS.

\section{Materials and methods}

Chemicals and standards

Nine MeO-PBDEs, 4-MeO-BDE42 (10 $\left.\mathrm{g} \mathrm{mL}^{-1}\right)$, 4'-MeOBDE49 $\left(10 \mu \mathrm{g} \mathrm{mL}^{-1}\right), 3-\mathrm{MeO}-\mathrm{BDE} 47\left(50 \mu \mathrm{g} \mathrm{mL}^{-1}\right), 5-\mathrm{MeO}-$ BDE47 $\left(50 \mu \mathrm{g} \mathrm{mL} \mathrm{mL}^{-1}\right), 6-\mathrm{MeO}-\mathrm{BDE} 47 \quad\left(10 \mu \mathrm{g} \mathrm{mL}^{-1}\right)$, 2'-MeO-BDE68 $\left(10 \mu \mathrm{g} \mathrm{mL}^{-1}\right)$, 6-MeO-BDE85 $\left(10 \mu \mathrm{g} \mathrm{mL}^{-1}\right)$, $5^{\prime}$-MeO-BDE99 $\left(10 \mu \mathrm{g} \mathrm{mL}^{-1}\right), 6^{\prime}$-MeO-BDE99 $\left(10 \mu \mathrm{g} \mathrm{mL}^{-1}\right)$, and ten OH-PBDEs, $3^{\prime}$-OH-BDE28 $\left(50 \mu \mathrm{g} \mathrm{mL}^{-1}\right), 4-\mathrm{OH}-\mathrm{BDE} 42$ $\left(10 \mu \mathrm{g} \mathrm{mL}^{-1}\right), 4^{\prime}-\mathrm{OH}-\mathrm{BDE} 49\left(10 \mu \mathrm{g} \mathrm{mL}^{-1}\right), 3-\mathrm{OH}-\mathrm{BDE} 47$ $\left(50 \mu \mathrm{g} \mathrm{mL}^{-1}\right)$, 5-OH-BDE47 $\left(50 \mu \mathrm{g} \mathrm{mL}^{-1}\right), 6-\mathrm{OH}-\mathrm{BDE} 47$ $\left(10 \mu \mathrm{g} \mathrm{mL}^{-1}\right), 2^{\prime}$-OH-BDE68 $\left(10 \mu \mathrm{g} \mathrm{mL}^{-1}\right), 6-\mathrm{OH}-\mathrm{BDE} 85$ $\left(10 \mu \mathrm{g} \mathrm{mL}^{-1}\right), 5^{\prime}$-OH-BDE99 $\left(10 \mu \mathrm{g} \mathrm{mL}^{-1}\right), 6^{\prime}$-OH-BDE99 $\left(10 \mu \mathrm{g} \mathrm{mL}^{-1}\right)$ were purchased from AccuStandard (New Haven, CT). Surrogate standards ${ }^{13} \mathrm{C}-6-\mathrm{MeO}-\mathrm{BDE} 47$ and ${ }^{13} \mathrm{C}-6-\mathrm{OH}-$ BDE47 at $50 \mu \mathrm{g} \mathrm{mL}^{-1}$, were purchased from Wellington (Guelph, ON). Individual MeO-PBDE working solutions were prepared at $500 \mathrm{ng} \mathrm{mL}^{-1}$ in hexane and OH-PBDE working solutions were prepared at $500 \mathrm{ng} \mathrm{mL}^{-1}$ in acetonitrile. HPLCgrade methyl tert-butyl ether (MTBE), methanol, acetonitrile, pesticide-grade hexane, and dichloromethane (DCM) were purchased from JT Baker (Phillipsburg, NJ) and Honeywell
Burdick \& Jackson (Seelze, Germany). Silica gel (0.063$0.100 \mathrm{~mm}$ ) was purchased from Merck (Darmstadt, Germany).

\section{Sample collection}

The Yellow Sea is a fairly shallow, semi-enclosed shelf sea of the north-western Pacific. It lies between the Chinese mainland and the Korean Peninsula, and joins the Bohai Sea in the north and the East China Sea (ECS) in the south. The Yellow Sea is separated into the SYS and the northern Yellow Sea by the Shandong Peninsula. The SYS covers an area of $309000 \mathrm{~m}^{2}$ and has a mean depth of $46 \mathrm{~m} .{ }^{\left[{ }^{32}\right]}$ The Yellow and Yangtze Rivers provide substantial sediment inputs to the SYS, although these two rivers do not flow directly into the SYS. ${ }^{[33]}$ Owing to the ample amount of terrigenous materials, including organic pollutants, carried by river-derived sediments entering the SYS, the area has become an environmental hotspot in recent decades. ${ }^{[32,34-36]}$ Thirty-seven surface sediment samples (depth: 0-3 cm) were collected from the coast to the central basin of the SYS during a cruise in April 2012 (Fig. 1), using a stainless steel box-corer from the R/V DongFangHong2 of the Ocean University of China, Qingdao, China. All samples were freezedried, homogenised, sieved through a stainless steel 75-mesh $(0.5-\mathrm{mm})$ sieve and stored at $-20^{\circ} \mathrm{C}$ until analysis.

\section{Analysis of MeO-PBDEs and OH-PBDEs, PBs and TOC}

Sample extraction, clean-up and instrumental conditions for analysis of MeO-PBDEs and OH-PBDEs were based on methods established by Sun et al. ${ }^{[37]}$ with some modifications. Briefly, samples were extracted in an ultrasonic bath with hexane/MTBE (1: $1 \mathrm{v} / \mathrm{v})$, cleaned with acid silica gel and a silica gel column, and then concentrated or solvent-exchanged before gas chromatography-mass spectroscopy (GC-MS) or liquid chromatography-mass spectroscopy (LC-MS) analysis. The detailed description of the methods can be found in our previous study. ${ }^{[25]}$ The procedures for analysing PBs followed previous methods. ${ }^{[38]}$

The freeze-dried sediment samples were treated with $4 \mathrm{~mol} \mathrm{~L}^{-1} \mathrm{HCl}$ to remove carbonate. After being rinsed with deionised water, the samples were dried in an oven at $55^{\circ} \mathrm{C}$. The carbonate-free samples were then measured for total organic carbon (TOC) in duplicate using a Thermo Flash 2000 elemental analyser (Thermo Scientific, Cambridge, UK), with a standard deviation of $0.02 \mathrm{wt}-\%(n=6)$. The standard Soil Reference $($ carbon $=3.50 \%$, Säntis Analytical AG) was used in the analysis.

\section{Quality assurance and quality control}

Seven-point standard calibration curves for MeO-PBDE and OH-PBDE quantification were prepared using standards for nine MeO-PBDEs and ten OH-PBDEs with concentrations ranging from 2 to $200 \mathrm{ng} \mathrm{mL}^{-1}$ as well as surrogate standards $\left({ }^{13} \mathrm{C}-6-\mathrm{MeO}-\mathrm{BDE} 47\right.$ and $\left.{ }^{13} \mathrm{C}-6-\mathrm{OH}-\mathrm{BDE} 47\right)$ with a concentration of $50 \mathrm{ng} \mathrm{mL}^{-1}$. Recovery tests for MeO-PBDEs and $\mathrm{OH}-$ PBDEs in a spiked matrix experiment ranged from 74 to $108 \%$ and from 71 to $93 \%$ respectively. Recoveries of ${ }^{13} \mathrm{C}-6-\mathrm{MeO}-$ BDE47 and ${ }^{13} \mathrm{C}-6-\mathrm{OH}-\mathrm{BDE} 47$ were 70 to $87 \%$ and 73 to $118 \%$. The method detection limits (MDLs) for individual compounds were estimated based on a signal-to-noise ratio of 3. MDLs for MeO-PBDEs and OH-PBDEs ranged from 11.7 to $21.1 \mathrm{pg} \mathrm{g}^{-1}$ dry weight (DW) and from 1.3 to $6.1 \mathrm{pg} \mathrm{g}^{-1} \mathrm{DW}$ respectively. All of the glassware was rinsed with DCM and hexane to prevent contamination. A method blank was coupled with every batch 


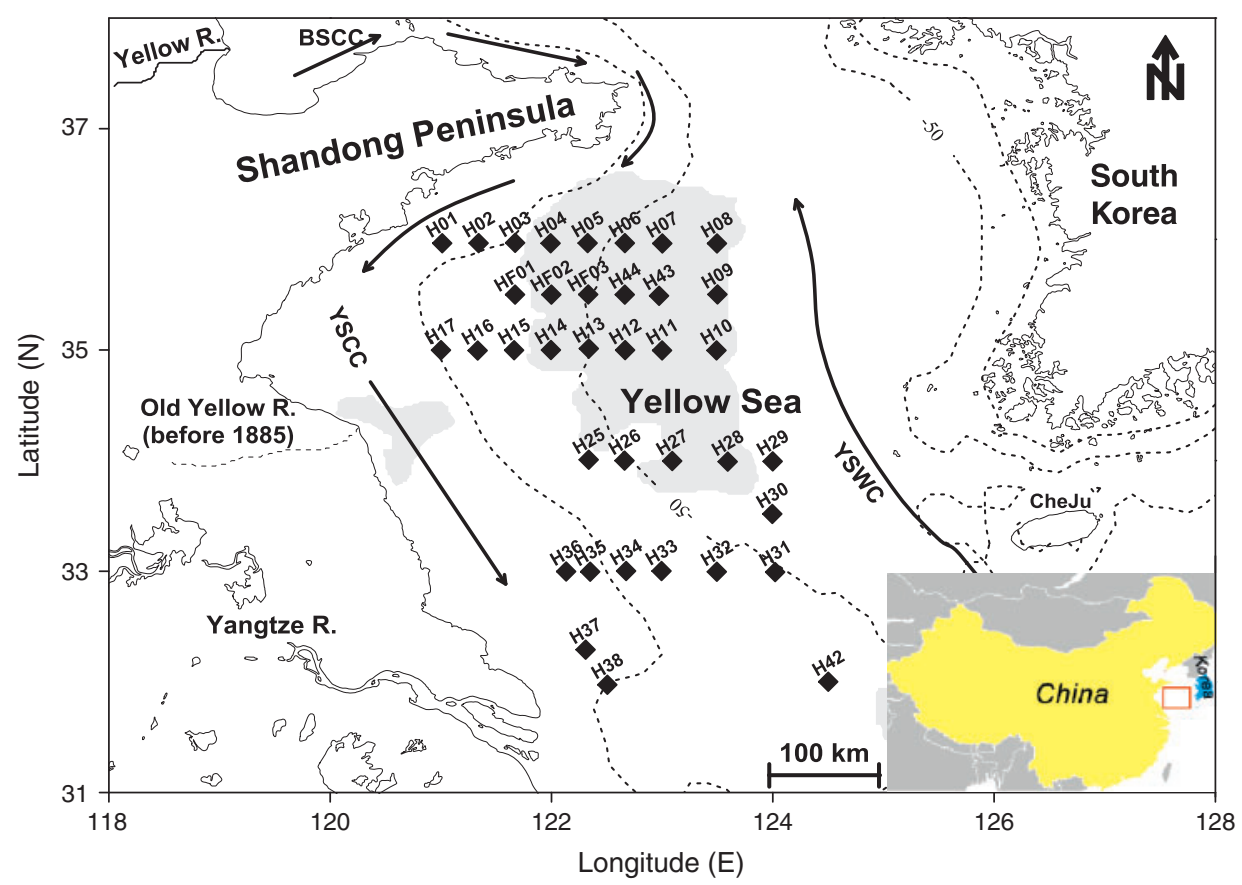

Fig. 1. Map of the study area and sampling sites. Mud areas are marked in light grey. Major currents are indicated by the curves with arrows: BSCC (Bohai Sea coastal current), YSCC (Yellow Sea coastal current) and YSWC (Yellow Sea warm current).

of six samples, and the concentrations of target compounds in the blanks were below MDLs.

\section{Results and discussion}

\section{Occurrence of MeO-PBDEs and OH-PBDEs}

Among the nine MeO-PBDEs (4-MeO-BDE42, 4'-MeOBDE49, 3-MeO-BDE47, 5-MeO-BDE47, 6-MeO-BDE47, 2'-MeO-BDE68, 6-MeO-BDE85, 5'-MeO-BDE99 and 6'-MeOBDE99) and ten OH-PBDEs (3'-OH-BDE28, 4-OH-BDE42, 4'-OH-BDE49, 3-OH-BDE47, 5-OH-BDE47, 6-OH-BDE47, 2'-OH-BDE68, 6-OH-BDE85, 5'-OH-BDE99 and 6'-OHBDE99) studied, only 6-MeO-BDE47, 2'-MeO-BDE68, 6-OHBDE47 and 2'-OH-BDE68 were detected in sediment samples, with a detection frequency of $89.2,40.5,100$ and $83.8 \%$ respectively. Total contents of these four compounds $(\Sigma \mathrm{MeO}-$ PDBEs and OH-PBDEs) ranged from 43.0 to $571.4 \mathrm{pg} \mathrm{g}^{-1} \mathrm{DW}$, with a mean value of $240.8 \mathrm{pg} \mathrm{g}^{-1} \mathrm{DW}$. These four compounds are also dominant in core sediments from the SYS ${ }^{[27]}$ and the ECS, ${ }^{[25]}$ surface sediments from the $\mathrm{ECS}^{[26]}$ and Liaodong Bay, ${ }^{[23]}$ and marine organisms from the Canadian Arctic ${ }^{[13]}$ and the Indian and South Atlantic Oceans. ${ }^{[20]}$

In all of the samples, 6-MeO-BDE47 contents (19.2 to $244.6 \mathrm{pg} \mathrm{g}^{-1} \mathrm{DW}$, mean value of $75.1 \mathrm{pg} \mathrm{g}^{-1} \mathrm{DW}$ ) were higher than those of $2^{\prime}$-MeO-BDE68 (24.1 to $113.8 \mathrm{pg} \mathrm{g}^{-1} \mathrm{DW}$, mean value of $\left.51.2 \mathrm{pg} \mathrm{g}^{-1} \mathrm{DW}\right)$. Higher 6-MeO-BDE47 contents, relative to $2^{\prime}$-MeO-BDE68, have also been reported in biotic media from the Canadian Arctic ${ }^{[13]}$ and sediments from the ECS $^{[26]}$ and Liaodong Bay. ${ }^{[23]}$ Moreover, contents of these dominant MeO-PBDEs were comparable with those in sediments from the ECS (5.2 to $599.5 \mathrm{pg} \mathrm{g}^{-1} \mathrm{DW}$, mean value of $93.2 \mathrm{pg} \mathrm{g}^{-1} \mathrm{DW}$, and 5.2 to $562.4 \mathrm{pg} \mathrm{g}^{-1} \mathrm{DW}$, mean value of $51.3 \mathrm{pg} \mathrm{g}^{-1}$ DW for 6-MeO-BDE47 and 2'-MeO-BDE68 respectively), ${ }^{[26]}$ and were significantly higher than those in sediments from Liaodong Bay $\left(15 \pm 1.6 \mathrm{pg} \mathrm{g}^{-1} \mathrm{DW}\right.$ for 6$\mathrm{MeO}-\mathrm{BDE} 47$ and $5.5 \pm 1.9 \mathrm{pg} \mathrm{g}^{-1} \mathrm{DW}$ for $\left.2^{\prime}-\mathrm{MeO}-\mathrm{BDE} 68\right),{ }^{[23]}$ White Lake in Michigan (2.6 $\mathrm{pg} \mathrm{g}^{-1}$ DW 6-MeO-BDE47), ${ }^{[39]}$ and the Kootenay River in Genelle, BC, Canada $\left(43.7 \pm 16 \mathrm{pg} \mathrm{g}^{-1} \mathrm{DW} 6-\mathrm{MeO}-\mathrm{BDE} 47\right) .{ }^{[40]}$ 6-OH-BDE47 and $2^{\prime}$-OH-BDE68 contents ranged from 39.2 to $223.5 \mathrm{pg} \mathrm{g}^{-1} \mathrm{DW}$ (mean of $101.6 \mathrm{pg} \mathrm{g}^{-1} \mathrm{DW}$ ) and 49.7 to $79.0 \mathrm{pg} \mathrm{g}^{-1} \mathrm{DW}$ (mean of $61.4 \mathrm{pg} \mathrm{g}^{-1} \mathrm{DW}$ ), which is significantly higher than those in sediments from Liaodong Bay $\left(22 \pm 2.3 \mathrm{pg} \mathrm{g}^{-1} \mathrm{DW}\right.$ for 6-OHBDE47 and $1.9 \pm 3.1 \mathrm{pg} \mathrm{g}^{-1}$ DW for $\left.2^{\prime}-O H-B D E 68\right)^{[23]}$ and the ECS (11.4 to $129.1 \mathrm{pg} \mathrm{g}^{-1}$ DW for 6-OH-BDE47, mean value of $\left.28.6 \mathrm{pg} \mathrm{g}^{-1} \mathrm{DW}\right){ }^{[26]}$

\section{Distributions of MeO-PBDEs and OH-PBDEs}

As shown in Fig. 2, 6-MeO-BDE47, 2'-MeO-BDE68, 6-OHBDE47 and $\Sigma \mathrm{MeO}-\mathrm{PDBEs}$ and OH-PBDEs contents showed similar seaward-increasing trends, with high-content areas in northern and southern parts of the central SYS basin. The contents of MeO-PBDEs and OH-PBDEs in surface sediments from the ECS also showed increasing trends from near-shore to offshore. ${ }^{[26]}$ The sediments deposited and accumulated in the central SYS basin are dominated by fine-grained materials, ${ }^{[35,41]}$ which show a high affinity for organic matter. ${ }^{[42]}$ Therefore, the accumulation of these MeO-PBDEs and $\mathrm{OH}-$ PBDEs in this region may also be attributed to the effect of grain size. Among the MeO-PBDEs and OH-PBDEs detected, 6$\mathrm{MeO}-\mathrm{BDE} 47$ and 6-OH-BDE47 showed very similar spatial patterns (Fig. 2a, c), with high levels at sites H04, H07, H08 and HF01 (Fig. 1) in the northern part and H28 in the southern part. The correspondence of spatial patterns suggests that these two compounds may to a great extent originate from the same sources. Fig. 2 b shows that high levels of $2^{\prime}$-MeO-BDE68 were located at sites $\mathrm{H} 08, \mathrm{H} 09, \mathrm{HF} 03$ and $\mathrm{H} 13$ in the northern part and $\mathrm{H} 28$ in the southern part. Compared with 6-MeO-BDE47 and 6-OHBDE47, 2'-MeO-BDE68 also showed a broadly similar pattern.

Organic matter (OM) is commonly considered an important factor influencing contaminant accumulation in sediments because of its high affinity for these compounds. ${ }^{[34,43]}$ In the current study, TOC contents (wt-\%) in all sediment samples 

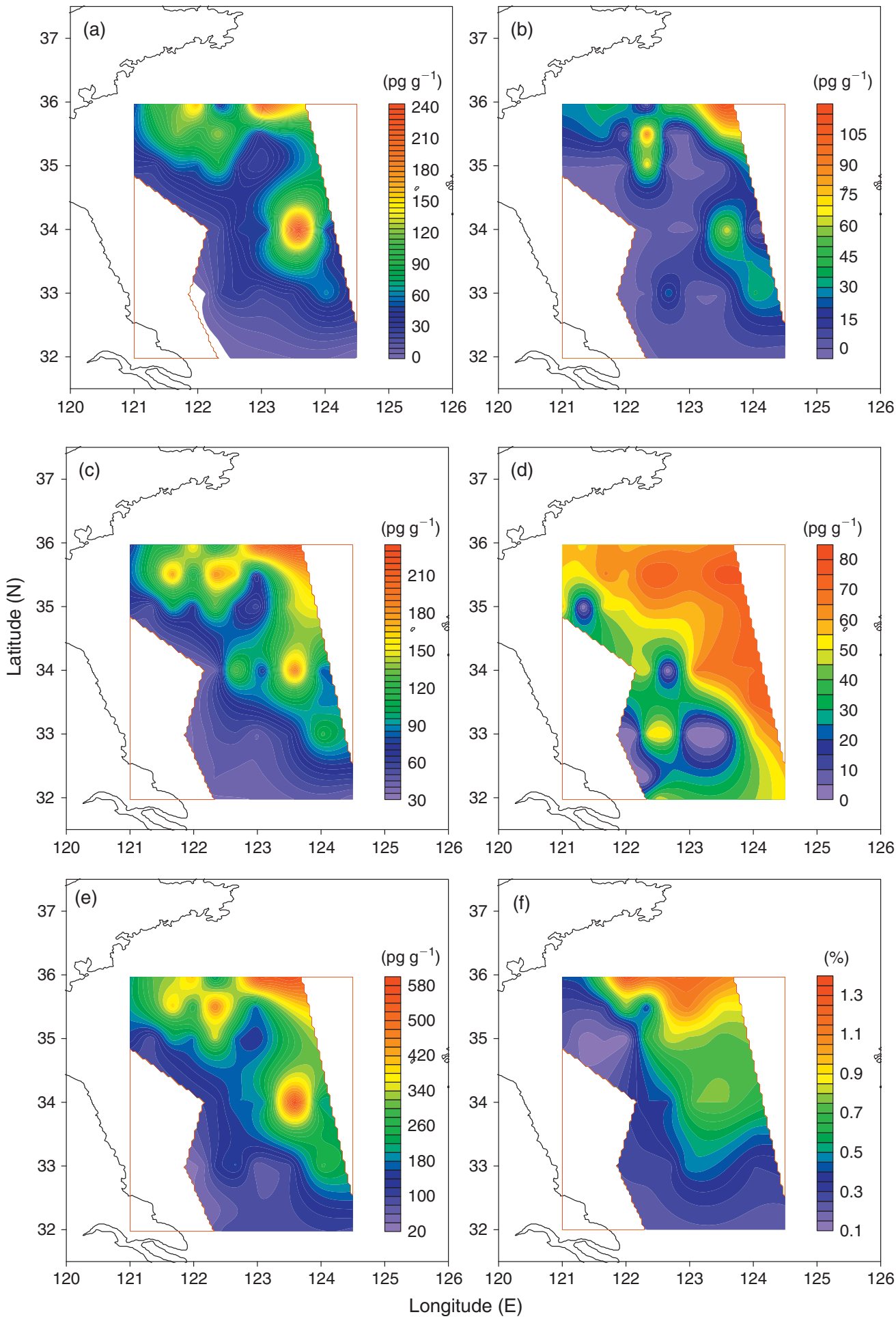

Fig. 2. Spatial distributions of methoxylated polybrominated diphenyl ethers (MeO-PBDEs) (a) 6-MeO-BDE47 and (b) 2'-MeO-BDE68; hydroxylated polybrominated diphenyl ethers (OH-PBDEs) (c) 6-OH-BDE47 and (d) 2'-OHBDE68); (e); $\Sigma \mathrm{MeO}-\mathrm{PDBEs}$ and $\mathrm{OH}-\mathrm{PBDEs}$ and (f) total organic carbon (TOC) in surface sediments from the southern Yellow Sea (SYS)

were also measured and they ranged from 0.11 to $1.33 \%$, with high values concentrated in the central SYS basin. The results are in accord with previous reports of TOC in the SYS. ${ }^{[35,41]}$ Significant correlations (Table 1) observed between TOC and most individual MeO-PBDEs and OH-PBDEs as well as $\Sigma \mathrm{MeO}-\mathrm{PDBEs}$ and OH-PBDEs suggest that TOC plays an important role in the accumulation of these MeO-PBDEs and
OH-PBDEs. ${ }^{[25,27]}$ A recent study by Xing et al. ${ }^{[44]}$ suggests that marine organic matter (MOM) is the major contributor to sedimentary TOC in the SYS, especially in the central basin. They argued that terrestrial organic matter (TOM) contributions were significantly higher near the coast, whereas MOM was predominant in the central basin. TOM contributions in SYS surface sediments presented a seaward-decreasing trend, ${ }^{[44]}$ 
Table 1. Pearson correlations $(P<\mathbf{0 . 0 5})$ between methoxylated polybrominated diphenyl ether $(\mathrm{MeO}-\mathrm{PBDE})$, hydroxylated polybrominated diphenyl ether (OH-PBDE) and total organic carbon (TOC) contents

Statistical analysis is based on normality assumption of the data. -, no significant correlation

\begin{tabular}{cccccc}
\hline & 6-MeO-BDE47 & 2'-MeO-BDE68 & 6-OH-BDE47 & 2'-OH-BDE68 $^{\prime}$ & $\Sigma$ MeO-PDBEs and OH-PBDEs \\
\hline TOC & 0.463 & - & 0.479 & 0.451 & 0.507 \\
\hline
\end{tabular}

Table 2. Pearson correlations $(P<0.05)$ between methoxylated polybrominated diphenyl ether $($ MeO-PBDE), hydroxylated polybrominated diphenyl ether (OH-PBDE) and phytoplankton biomarker (PB) contents

Statistical analysis is based on normality assumption of the data. -, no significant correlation

\begin{tabular}{lcccc}
\hline & Brassicasterol (B) & Dinosterol (D) & Alkenones (A) & $\Sigma \mathrm{B}+\mathrm{D}+\mathrm{A}$ \\
\hline 6-MeO-BDE47 & 0.669 & 0.677 & 0.453 & 0.711 \\
2'-MeO-BDE68 & 0.724 & 0.808 & 0.551 & 0.818 \\
6-OH-BDE47 & 0.718 & 0.739 & 0.608 & 0.790 \\
2'-OH-BDE68 & - & 0.467 & - & 0.471 \\
\hline
\end{tabular}

totally opposite to those of MeO-PBDEs and OH-PBDEs in our study (Fig. 2a-e). Because there is no large river (such as the Yellow and Yangtze Rivers) directly flowing into SYS, we propose that these compounds mainly originate from marine production rather than from terrigenous inputs. This supposition corresponds with findings from sedimentary records in the SYS, which is the natural origin of MeO-PBDEs and OH-PBDEs, indicated by their detection in the 1800 s before the production of PBDEs. ${ }^{[27]}$

\section{Potential producers of MeO-PBDEs and OH-PBDEs}

In the SYS, diatoms, dinoflagellates and coccolithophorids are the dominant and important phytoplankton, constituting the main component of primary productivity in the SYS. ${ }^{[45-47]}$ Brassicasterol, dinosterol and $\mathrm{C}_{37}$ alkenones (alkenones) are mainly produced by diatoms, dinoflagellates and coccolithophorids respectively. ${ }^{[48]}$ Thus, their individual and total contents are reliable indicators for reflecting the biomass of corresponding producer and primary productivity in the euphotic layer. ${ }^{[29,30,38,44]}$ These three PBs were also detected in all sediment samples. Correlation analysis shows that there are significant positive correlations between the contents of most compounds (Table 2), except for 2'-OH-BDE68 and brassicasterol, as well as alkenones. Such intimate relationships between $\mathrm{MeO}-\mathrm{PBDEs}$ and $\mathrm{OH}-\mathrm{PBDEs}$ and $\mathrm{PBs}$ were also revealed in two sediment cores obtained from the shelf of ECS. ${ }^{[25]}$ Previous studies have reported that 6-OH-BDE47, 2'-OH-BDE68, 6$\mathrm{MeO}-\mathrm{BDE} 47$ and $2^{\prime}$-MeO-BDE68 are the dominant MeOPBDE and OH-PBDE congeners in algae. ${ }^{[6,7]}$ Therefore, as previously proposed, ${ }^{[19,25,26]}$ phytoplankton are likely to be more important producers of MeO-PBDEs and OH-PBDEs compared with sponges and their symbiotic cyanobacteria, ${ }^{[49]}$ which are mainly located in tropical oceans.

Fig. 3 shows that the content ratios of brassicasterol to dinosterol (B/D) present a completely opposite pattern to the contents of $\Sigma \mathrm{MeO}$-PDBEs and OH-PBDEs, decreasing with a near-shore-offshore trend. Previous studies have reported that content ratios of $\mathrm{PBs}$ are reliable indicators for reconstructing changes of the phytoplankton community structure because of their similar diagenetic properties and fairly good preservation in sediments. ${ }^{[29,31,50]}$ Thus, the spatial pattern of $\mathrm{B} / \mathrm{D}$ ratios

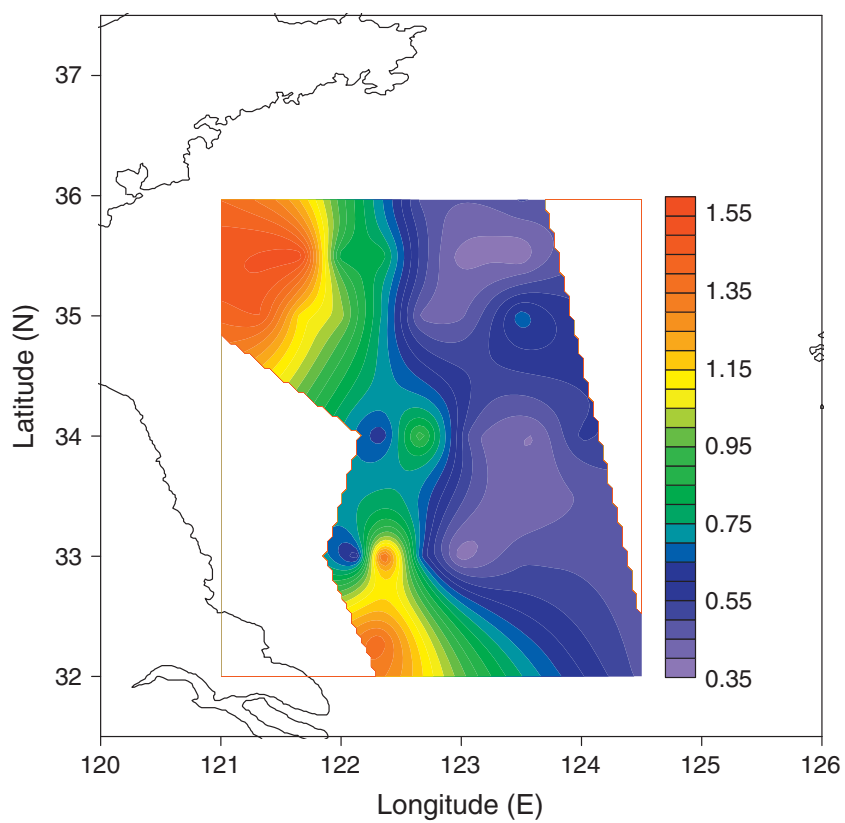

Fig. 3. Spatial distributions of content ratios of brassicasterol to dinosterol in surface sediments from the southern Yellow Sea (SYS).

indicates more dinoflagellates than diatoms in the offshore SYS. As revealed in Fig. 2, more MeO-PBDEs and OH-PBDEs were found in the central SYS basin, which suggests that dinoflagellates are prone to produce MeO-PBDEs and OH-PBDEs. This result is in agreement with previous findings that distributions of these compounds may be controlled by the phytoplankton community. ${ }^{[25]}$ Also shown in Table 2 is that MeO-PBDEs and $\mathrm{OH}-\mathrm{PBDEs}$ have relatively better correlations with dinosterol than with brassicasterol.

\section{Linkages between MeO-PBDEs and OH-PBDEs}

Many studies have reported the co-occurrence of MeO-PBDE and OH-PBDE pairs in marine organisms and sediments. ${ }^{[8,11,20,23,25,27,51]}$ Because OH-PBDEs exhibit greater toxicity than the corresponding MeO-PBDEs, relationships between MeO-PBDEs and $\mathrm{OH}-\mathrm{PBDEs}$ in marine environments 


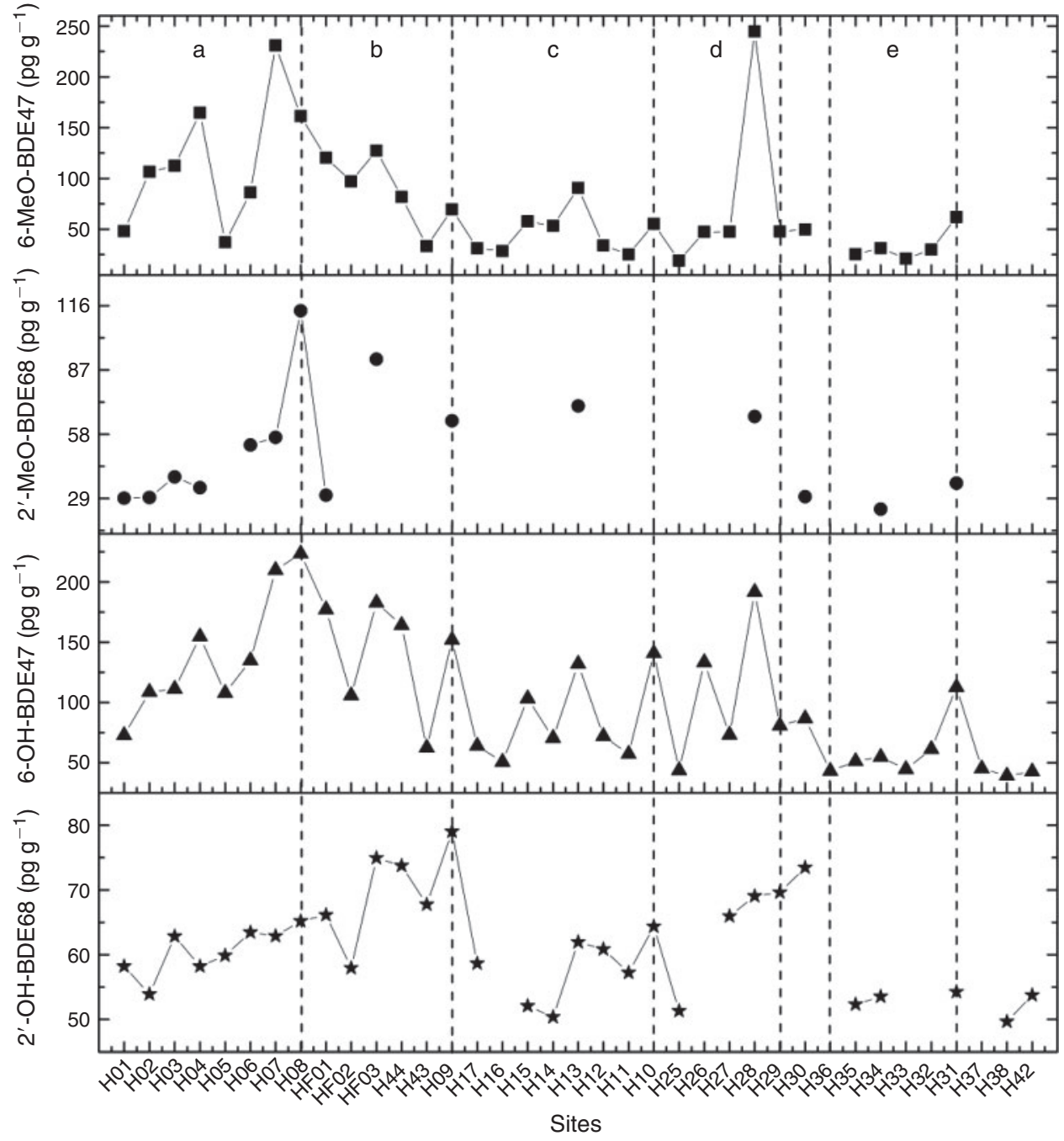

Fig. 4. Variations in methoxylated polybrominated diphenyl ether (MeO-PBDE) and hydroxylated polybrominated diphenyl ether (OH-PBDE) contents in surface sediments from different near-shore-offshore transects (a-e) of the southern Yellow Sea (SYS).

should be of concern. Wiseman et al. ${ }^{[52]}$ suggested that a correlation between such pairs can be considered as a nondefinitive indicator of their metabolic relationships. Based on in vitro and in vivo exposure studies, the significant correlation between 6-OH-BDE47 and 6-MeO-BDE47 observed in marine organism was attributed to their interconversion. ${ }^{[20,21]}$ Recently, this interconversion was also found to occur in incubated marine sediments, and was attributed to bacterial $O$-methylation reactions, although the conversion ratio of 6-OH-BDE47 to 6-MeOBDE47 $(0.824 \pm 0.052)$ is significantly higher than that of 6-MeO-BDE47 to 6-OH-BDE47 $(0.010 \pm 0.002){ }^{[23,53]}$

In the present study, contents of 6-OH-BDE47 and 6-MeOBDE47 presented similar near-shore-offshore trends in all five transects (Fig. 4). Correlation analysis shows that there is a strong positive relationship between sedimentary contents of these two compounds $(r=0.846, P<0.05)$. This similarity implies the occurrence of conversion between 6-OH-BDE47 and 6-MeO-BDE47 in sediments. ${ }^{[23,52]}$ Considering the much lower conversion ratio from 6-MeO-BDE47 to 6-OH-BDE47 $(0.010 \pm 0.002),{ }^{[23]}$ comparable contents of these two compounds in most samples suggest that a large proportion of 6-OH-BDE47 in surface sediments from the SYS may originate from direct production by marine organisms rather than from the conversion from 6-MeO-BDE47.

\section{Conclusions}

Concentrations of MeO-PBDEs and OH-PBDEs in SYS surface sediments generally presented a seaward-increasing trend, with a dominance of 6-MeO-BDE47, 2'-MeO-BDE68, 6-OH-BDE47 and $2^{\prime}-\mathrm{OH}-\mathrm{BDE} 68$. High-content areas of these compounds were concentrated in the central basin. Similarities in occurrence and significant correlations between MeO-PBDEs and $\mathrm{OH}-\mathrm{PBDEs}$ observed in sediment samples suggest same sources for these compounds and the interconversion of 6-MeO-BDE47 and 6-OH-BDE47. Comparisons with TOC and PBs suggest that $\mathrm{MeO}-\mathrm{PBDEs}$ and $\mathrm{OH}-\mathrm{PBDE}$ detected in the SYS are natural compounds probably produced by the phytoplankton, and their distributions may be controlled by the phytoplankton community and TOC.

\section{Acknowledgements}

The present study was supported by National Natural Science Foundation (grant numbers 41221004, 21407086, 21477138 and 41106038), the China 
Postdoctoral Science Foundation (2013M541052) and Doctor Fund of Qingdao Agricultural University (63311330). We thank Hailong Zhang and $\mathrm{Li} \mathrm{Li}$ for technical assistance. We also thank the crew of R/V DongFangHong2 of the Ocean University of China for the assistance in sediment coring. This is MCTL contribution number 68.

\section{References}

[1] R. J. Law, C. R. Allchin, J. de Boer, A. Covaci, D. Herzke, P. Lepom, S. Morris, J. Tronczynski, C. A. de Wit, Levels and trends of brominated flame retardants in the European environment. Chemosphere 2006, 64, 187. doi:10.1016/J.CHEMOSPHERE.2005.12.007

[2] I. A. T. M. Meerts, R. J. Letcher, S. Hoving, G. Marsh, A. Bergman, J. G. Lemmen, B. van der Burg, A. Brouwer, In vitro estrogenicity of polybrominated diphenyl ethers, hydroxylated PBDEs, and polybrominated bisphenol A compounds. Environ. Health Perspect. 2001, 109, 399. doi:10.1289/EHP.01109399

[3] M. M. Dingemans, A. de Groot, R. G. van Kleef, A. Bergman, M. van den Berg, H. P. Vijverberg, R. H. Westerink, Hydroxylation increases the neurotoxic potential of BDE-47 to affect exocytosis and calcium homeostasis in PC12 cells. Environ. Health Perspect. 2008, 116, 637. doi:10.1289/EHP.11059

[4] G. Su, J. Xia, H. Liu, M. H. W. Lam, H. Yu, J. P. Giesy, X. Zhang, Dioxin-like potency of $\mathrm{HO}$ - and $\mathrm{MeO}-$ analogues of PBDEs' the potential risk through consumption of fish from Eastern China. Environ. Sci. Technol. 2012, 46, 10 781. doi:10.1021/ES302317Y

[5] Y. He, M. B. Murphy, R. M. K. Yu, M. H. W. Lam, M. Hecker, J. P. Giesy, R. S. S. Wu, P. K. S. Lam, Effects of 20 PBDE metabolites on steroidogenesis in the H295R cell line. Toxicol. Lett. 2008, 176, 230. doi:10.1016/J.TOXLET.2007.12.001

[6] M. Kuniyoshi, K. Yamada, T. Higa, A biologically active diphenyl ether from the green alga Cladophora fascicularis. Cell. Mol. Life Sci. 1985, 41, 523. doi: $10.1007 /$ BF01966182

[7] L. Asplund, A. Malmvärn, G. Marsh, M. Athanasiadou, Å. Bergman, L. Kautsky, Hydroxylated brominated diphenyl ethers in salmon (Salmo salar), blue mussels (Mytilus edulis) and the red algae (Ceramium tenuicorne) from the Baltic Sea - natural production in Baltic Sea biota. Organohalogen Compd. 2001, 52, 67.

[8] A. Malmvärn, G. Marsh, L. Kautsky, M. Athanasiadou, Å. Bergman, L. Asplund, Hydroxylated and methoxylated brominated diphenyl ethers in the red algae Ceramium tenuicorne and blue mussels from the Baltic Sea. Environ. Sci. Technol. 2005, 39, 2990. doi:10.1021/ ES0482886

[9] A. Malmvärn, Y. Zebühr, L. Kautsky, Å. Bergman, L. Asplund, Hydroxylated and methoxylated polybrominated diphenyl ethers and polybrominated dibenzo-p-dioxins in red alga and cyanobacteria living in the Baltic Sea. Chemosphere 2008, 72, 910. doi:10.1016/ J.CHEMOSPHERE.2008.03.036

[10] K. Valters, H. Li, M. Alaee, I. D'Sa, G. Marsh, A. Bergman, R. J. Letcher, Polybrominated diphenyl ethers and hydroxylated and methoxylated brominated and chlorinated analogues in the plasma of fish from the Detroit River. Environ. Sci. Technol. 2005, 39, 5612. doi:10.1021/ES0506410

[11] K. Zhang, Y. Wan, J. P. Giesy, M. H. W. Lam, S. Wiseman, P. D. Jones, J. Hu, Tissue concentrations of polybrominated compounds in Chinese Sturgeon (Acipenser sinensis): origin, hepatic sequestration, and maternal transfer. Environ. Sci. Technol. 2010, 44, 5781. doi:10.1021/ES100348G

[12] X. Fu, F. J. Schmitz, M. Govindan, S. A. Abbas, K. M. Hanson, P. A. Horton, P. Crews, M. Laney, R. C. Schatzman, Enzyme inhibitors: new and known polybrominated phenols and diphenyl ethers from four Indo-Pacific Dysidea sponges. J. Nat. Prod. 1995, 58, 1384. doi:10.1021/NP50123A008

[13] B. C. Kelly, M. G. Ikonomou, J. D. Blair, F. A. P. C. Gobas, Hydroxylated and methoxylated polybrominated diphenyl ethers in a Canadian Arctic marine food web. Environ. Sci. Technol. 2008, 42, 7069. doi:10.1021/ES801275D

[14] F. Liu, S. Wiseman, Y. Wan, J. A. Doering, M. Hecker, M. H. W. Lam, J. P. Giesy, Multispecies comparison of the mechanism of biotransformation of MeO-BDEs to OH-BDEs in fish. Aquat. Toxicol. 2012, 114-115, 182. doi:10.1016/J.AQUATOX.2012.02.024

[15] H. Stapleton, S. Kelly, R. Pei, R. Letcher, C. Gunsch, Metabolism of polybrominated diphenyl ethers (PBDEs) by human hepatocytes in vitro. Environ. Health Perspect. 2009, 117, 197. doi:10.1289/ EHP. 11807

[16] S. Lacorte, M. G. Ikonomou, Occurrence and congener specific profiles of polybrominated diphenyl ethers and their hydroxylated and methoxylated derivatives in breast milk from Catalonia. Chemosphere 2009, 74, 412. doi:10.1016/J.CHEMOSPHERE.2008. 09.050

[17] L. Hovander, T. Malmberg, M. Athanasiadou, I. Athanassiadis, S. Rahm, Å. Bergman, E. Klasson Wehler, Identification of hydroxylated PCB metabolites and other phenolic halogenated pollutants in human blood plasma. Arch. Environ. Contam. Toxicol. 2002, 42, 105. doi: $10.1007 / \mathrm{S} 002440010298$

[18] E. L. Teuten, L. Xu, C. M. Reddy, Two abundant bioaccumulated halogenated compounds are natural products. Nat. Prod. Sci. 2005, 307, 917.

[19] C. Guitart, M. Slattery, S. Ankisetty, M. Radwan, S. J. Ross, R. J. Letcher, C. M. Reddy, Contemporary ${ }^{14} \mathrm{C}$ radiocarbon levels of oxygenated polybrominated diphenyl ethers (O-PBDEs) isolated in sponge-cyanobacteria associations. Mar. Pollut. Bull. 2011, 62, 631. doi:10.1016/J.MARPOLBUL.2010.12.022

[20] Y. Wan, S. Wiseman, H. Chang, X. Zhang, P. D. Jones, M. Hecker, K. Kannan, S. Tanabe, J. Hu, M. H. W. Lam, J. P. Giesy, Origin of hydroxylated brominated diphenyl ethers: natural compounds or man-made flame retardants? Environ. Sci. Technol. 2009, 43, 7536. doi:10.1021/ES901357U

[21] Y. Wan, F. Liu, S. Wiseman, X. Zhang, H. Chang, M. Hecker, P. D. Jones, M. H. W. Lam, J. P. Giesy, Interconversion of hydroxylated and methoxylated polybrominated diphenyl ethers in Japanese medaka. Environ. Sci. Technol. 2010, 44, 8729. doi:10.1021/ES102287Q

[22] S. Losada, A. Roach, L. Roosens, F. J. Santos, M. T. Galceran, W. Vetter, H. Neels, A. Covaci, Biomagnification of anthropogenic and naturally produced organobrominated compounds in a marine food web from Sydney harbour, Australia. Environ. Int. 2009, 35, 1142. doi:10.1016/J.ENVINT.2009.07.008

[23] K. Zhang, Y. Wan, P. D. Jones, S. Wiseman, J. P. Giesy, J. Hu, Occurrences and fates of hydroxylated polybrominated diphenyl ethers in marine sediments in relation to trophodynamics. Environ. Sci. Technol. 2012, 46, 2148. doi:10.1021/ES203195S

[24] W. Vetter, P. Haase-Aschoff, N. Rosenfelder, T. Komarova, J. F. Mueller, Determination of halogenated natural products in passive samplers deployed along the Great Barrier Reef, Queensland, Australia. Environ. Sci. Technol. 2009, 43, 6131. doi:10.1021/ ES900928M

[25] Y. Fan, C.-A. Huh, J. Lan, M. Zhao, Z. Zhao, G. Li, J. Sun, G. Jiang, Major sources of $\mathrm{MeO} / \mathrm{OH}-\mathrm{BDEs}$ in the East China Sea elucidated from their records and phytoplankton biomarkers. Environ. Pollut. 2014, 192, 1. doi:10.1016/J.ENVPOL.2014.04.037

[26] Y. Fan, J. Lan, H. Li, G. Li, Y. Cao, Z. Zhao, M. Zhao, G. Jiang, Spatial distributions of methoxylated and hydroxylated polybrominated diphenyl ethers in the East China Sea - a seaward-increasing trend. Chemosphere 2014, 114, 247. doi:10.1016/J.CHEMOSPHERE. 2014.04.103

[27] Y. Fan, J. Lan, Z. Zhao, M. Zhao, Sedimentary records of hydroxylated and methoxylated polybrominated diphenyl ethers in the southern Yellow Sea. Mar. Pollut. Bull. 2014, 84, 366. doi:10.1016/J.MAR POLBUL.2014.05.035

[28] G. W. Gribble, The diversity of naturally produced organohalogens. Chemosphere 2003, 52, 289. doi:10.1016/S0045-6535(03)00207-8

[29] C. J. Schubert, J. Villanueva, S. E. Calvert, G. L. Cowie, U. von Rad, H. Schulz, U. Berner, H. Erlenkeuser, Stable phytoplankton community structure in the Arabian Sea over the past 200000 years. Nature 1998, 394, 563. doi:10.1038/29047

[30] M. Zhao, J. L. Mercer, G. Eglinton, M. J. Higginson, C.-Y. Huang, Comparative molecular biomarker assessment of phytoplankton paleoproductivity for the last $160 \mathrm{kyr}$ off Cap Blanc, NW Africa. 
Org. Geochem. 2006, 37, 72. doi:10.1016/J.ORGGEOCHEM.2005. 08.022

[31] L. Xing, R. Zhang, Y. Liu, X. Zhao, S. Liu, X. Shi, M. Zhao Biomarker records of phytoplankton productivity and community structure changes in the Japan Sea over the last 166 kyr. Quat. Sci. Rev. 2011, 30, 2666. doi:10.1016/J.QUASCIREV.2011.05.021

[32] P. Zhang, J. Song, Z. Liu, G. Zheng, N. Zhang, Z. He, PCBs and its coupling with eco-environments in southern Yellow Sea surface sediments. Mar. Pollut. Bull. 2007, 54, 1105. doi:10.1016/J.MAR POLBUL.2007.05.005

[33] D. Cai, X. Shi, W. Zhou, W. Liu, S. Zhang, Y. Cao, Y. Han, Sources and transportation of suspended matter and sediment in the southern Yellow Sea: evidence from stable carbon isotopes. Chin. Sci. Bull. 2003, 48, 21. doi:10.1007/BF02900936

[34] P. Zhang, J. Song, J. Fang, Z. Liu, X. Li, H. Yuan, One century record of contamination by polycyclic aromatic hydrocarbons and polychlorinated biphenyls in core sediments from the southern Yellow Sea. J. Environ. Sci. 2009, 21, 1080. doi:10.1016/S1001-0742(08) 62385-2

[35] X. Duan, Y. Li, X. Li, D. Zhang, M. Li, Polychlorinated biphenyls in sediments of the Yellow Sea: distribution, source identification and flux estimation. Mar. Pollut. Bull. 2013, 76, 283. doi:10.1016/J.MAR POLBUL.2013.08.024

[36] L. Zeng, R. Chen, Z. Zhao, T. Wang, Y. Gao, A. Li, Y. Wang, G. Jiang, L. Sun, Spatial distributions and deposition chronology of shortchain chlorinated paraffins in marine sediments across the Chinese Bohai and Yellow Seas. Environ. Sci. Technol. 2013, 47, 11449 doi:10.1021/ES402950Q

[37] J. Sun, J. Liu, Q. Liu, G. Qu, T. Ruan, G. Jiang, Sample preparation method for the speciation of polybrominated diphenyl ethers and their methoxylated and hydroxylated analogues in diverse environmental matrices. Talanta 2012, 88, 669. doi:10.1016/J.TALANTA.2011. 11.059

[38] L. Xing, H. Zhang, Z. Yuan, Y. Sun, M. Zhao, Terrestrial and marine biomarker estimates of organic matter sources and distributions in surface sediments from the East China Sea shelf. Cont. Shelf Res. 2011, 31, 1106. doi:10.1016/J.CSR.2011.04.003

[39] P. W. Bradley, Y. Wan, P. D. Jones, S. Wiseman, H. Chang, M. H. W Lam, D. T. Long, J. P. Giesy, PBDEs and methoxylated analogues in sediment cores from two Michigan, USA, inland lakes. Environ. Toxicol. Chem. 2011, 30, 1236. doi:10.1002/ETC.500

[40] S. Lacorte, M. G. Ikonomou, M. Fischer, A comprehensive gas chromatography coupled to high-resolution mass spectrometry-based method for the determination of polybrominated diphenyl ethers and their hydroxylated and methoxylated metabolites in environmental samples. J. Chromatogr. A 2010, 1217, 337. doi:10.1016/J.CHROMA. 2009.11.024
[41] L. Hu, X. Shi, Z. Guo, H. Wang, Z. Yang, Sources, dispersal and preservation of sedimentary organic matter in the Yellow Sea: the importance of depositional hydrodynamic forcing. Mar. Geol. 2013, 335, 52. doi:10.1016/J.MARGEO.2012.10.008

[42] S. Lin, I. J. Hsieh, K.-M. Huang, C.-H. Wang, Influence of the Yangtze River and grain size on the spatial variations of heavy metals and organic carbon in the East China Sea continental shelf sediments. Chem. Geol. 2002, 182, 377. doi:10.1016/S0009-2541(01)00331-X

[43] F. M. Dunnivant, J. T. Coates, A. W. Elzerman, Labile and non-labile desorption rate constants for 33 PCB congeners from lake sediment suspensions. Chemosphere 2005, 61, 332. doi:10.1016/J.CHEMO SPHERE.2005.02.092

[44] L. Xing, S. Tao, H. Zhang, Y. Liu, Z. Yu, M. Zhao, Distributions and origins of lipid biomarkers in surface sediments from the southern Yellow Sea. Appl. Geochem. 2011, 26, 1584. doi:10.1016/J.APGEO CHEM.2011.06.024

[45] J. Wang, Study on phytoplankton in the Yellow Sea in autumn and winter. Mar. Fish. Res. 2003, 24, 15. [In Chinese].

[46] J. Sun, S. Jin, Species diversity of living coccolithophores in Chinese sea waters. Biodivers. Sci. 2011, 19, 787. [In Chinese].

[47] W. Tian, J. Sun, Later spring phytoplankton community in the Southern Yellow Sea in 2009. Mar. Sci. 2011, 35, 19. [In Chinese].

[48] J. K. Volkman, S. M. Barrett, S. I. Blackburn, M. P. Mansour, E. L. Sikes, F. Gelin, Microalgal biomarkers: a review of recent research developments. Org. Geochem. 1998, 29, 1163. doi:10.1016/S01466380(98)00062-X

[49] D. J. Faulkner, M. D. Unson, C. A. Bewley, The chemistry of some sponges and their symbionts. Pure Appl. Chem. 1994, 66, 1983. doi:10.1351/PAC199466101983

[50] K. U. Hinrichs, R. R. Schneider, P. J. Müller, J. Rullkötter, A biomarker perspective on paleoproductivity variations in two Late Quaternary sediment sections from the south-east Atlantic Ocean. Org. Geochem. 1999, 30, 341. doi:10.1016/S0146-6380(99)00007-8

[51] G. Marsh, M. Athanasiadou, A. Bergman, L. Asplund, Identification of hydroxylated and methoxylated polybrominated diphenyl ethers in Baltic Sea Salmon (Salmo salar) blood. Environ. Sci. Technol. 2004, 38, 10. doi:10.1021/ES034671J

[52] S. B. Wiseman, Y. Wan, H. Chang, X. Zhang, M. Hecker, P. D. Jones, J. P. Giesy, Polybrominated diphenyl ethers and their hydroxylated/ methoxylated analogs: environmental sources, metabolic relationships, and relative toxicities. Mar. Pollut. Bull. 2011, 63, 179. doi:10.1016/J.MARPOLBUL.2011.02.008

[53] A. S. Allard, M. Remberger, A. H. Neilson, Bacterial $O$-methylation of halogen-substituted phenols. Appl. Environ. Microbiol. 1987, 53,839 . 